\title{
Geoarchaeological Prospection of a Medieval Manor in the Dutch Polders Using an Electromagnetic Induction Sensor in Combination with Soil Augerings
}

\section{David Simpson, ${ }^{1, *}$ Alexander Lehouck, ${ }^{2,4, *}$ Marc Van Meirvenne, ${ }^{1}$ Jean Bourgeois, ${ }^{3}$ Erik Thoen,${ }^{2}$ and Jelier Vervloet ${ }^{4}$}

${ }^{1}$ Department of Soil Management and Soil Care, Ghent University, Coupure 653, B-9000 Gent, Belgium

${ }^{2}$ Department of Medieval History, Ghent University, Blandijnberg 2, B-9000 Gent, Belgium

${ }^{3}$ Department of Archaeology and Ancient History of Europe, Ghent University, Blandijnberg 2, B-9000 Gent, Belgium

${ }^{4}$ Department Environmental Sciences, Wageningen University and

Research Centre, P.O. Box 4\%, NL-6700 AA Wageningen, The Netherlands

\begin{abstract}
In archaeological prospection, geophysical sensors are increasingly being used to locate buried remains within their natural context. To cover a large area in sufficient detail, an electromagnetic induction sensor can be very useful, measuring simultaneously the electrical conductivity and the magnetic susceptibility of the soil (e.g., Geonics EM38DD). In this study, an 8 ha field containing a Medieval manor was mapped in a submeter resolution, using a mobile sensor configuration equipped with a GPS. As different soil features can yield analogous responses, the interpretation of geophysical maps can be ambiguous. Therefore, soil auger observations were laid out along two perpendicular transects to provide vertical profiles across the sensor measurements. This information greatly enhanced the interpretation of the anomalies obtained by the sensor. Both natural and anthropogenic features were delineated, which clearly presented a moated site along a former tidal channel. (C) 2008 Wiley Periodicals, Inc.
\end{abstract}

\section{INTRODUCTION}

Archaeological prospection focuses mostly on detecting small-scale features like buried walls or ditches. This requires very high density observations, so for practical reasons observations are often limited to a restricted area of interest. On the other hand, to survey a larger area encompassing the site of interest has significant

*Corresponding authors; Tel: +32 (0)9 26458 69; Fax: +32 (0)9 2646247.

E-mail: David.Simpson@UGent.be (David Simpson); Alexander.Lehouck@WUR.nl(Alexander Lehouck).

Geoarchaeology: An International Journal, Vol. 23, No. 2, 305-319 (2008) (C) 2008 Wiley Periodicals, Inc. 
advantages: (1) to detect other relevant features related to the site, (2) to compare sitespecific anomalies with the surrounding measurements, and (3) to map the natural context of the site. To answer the demand for large-area, high-density measurements, geophysicists have developed sensors on mobile platforms with GPS positioning that allow them to record thousands of measurements in one day (Hill, Grossey, \& Leech, 2004; Rabbel, Stuempel, \& Woelz, 2004). Different physical properties give rise to a range of contrasting anomalies that can be observed by soil sensors. Therefore, integrating multiple sensors on one platform, such as geoelectric, magnetic, and radar sensors, can increase the detection level (Kvamme, 2006).

In this investigation a Slingram electromagnetic induction (EMI) sensor was used. EMI sensors have been applied for a long time in archaeological prospection (e.g., Tabbagh, 1984). The type of sensor we used is the "EM38" manufactured by Geonics (Ontario, Canada), with dual dipole configuration, called "EM38DD." This dipole configuration allows the user to measure simultaneously two important physical properties in geoarchaeological prospection: apparent electrical conductivity (ECa) and magnetic susceptibility (MS). The EM38 has two other advantages for mobile measurements: It is noninvasive and it is small and lightweight so it can be transported easily on a sled. In spite of the advantages, EMI sensors are used less often than magnetometers and resistivity sensors in archaeological prospection. According to Tabbagh (1990), EMI sensors are less sensitive to resistive targets than resistivity sensors, which could limit the detection of resistive features such as stone walls. When the soil is low in electrical conductivity, conductivity anomalies are influenced by the magnetic response. This was also found by Linford (1998), who observed that the conductivity anomalies of the EM38 were more related to magnetometer than to resistivity meter anomalies in a low electrical conductive environment. Apart from the sensitivity difference in electrical prospecting, EMI sensors also have a different spatial sensitivity, which is dependent on instrument properties such as coil distance and orientation (Geonics, 1998). This geometrical factor is also important when measuring the MS. Benech and Marmet (1999) found greater depth sensitivity for a Slingram EMI sensor than for a coincident loop sensor, but according to Tabbagh (1984) a $1.5 \mathrm{~m}$ coil spaced EMI instrument is less sensitive to deep anomalies than a magnetometer. Furthermore, EMI instruments are insensitive to remanent magnetism, because the measured magnetic field is generated by the sensor itself, whereas magnetometers passively measure the variations of the earth's magnetic field (Desvignes and Tabbagh, 1995).

The different sensitivities in depth and in physical properties are probably the reasons why EMI sensors are less used in archaeological investigations than, for example, magnetometer or resistivity methods. Maillol, Ciobotaru, and Moravetz (2004) compared an EM38 sensor measuring the ECa in the vertical dipole orientation with a proton magnetometer and concluded that the EM38 was disappointing in detecting the Neolithic site features. But they did not measure in the horizontal coil orientation or use the in-phase MS mode. Venter et al. (2006) mention that they used an EM38 "because of considerations of budget limitations, portability of equipment, speed of coverage and quick processing," where they would have preferred to use multiple sensors, but the results of the survey were good. In some circumstances, 
EMI can detect the subsurface features better than other methods; e.g., Lück and Eisenreich (1999), using an EM38, detected two circular ditch systems that were not identified with either a Fluxgate or a Caesium magnetometer. These examples show that the effectiveness of electromagnetic induction is still questioned by many researchers. In this research, both the ECa and MS were measured to see whether they provide complementary information, valuable for archaeological prospection.

Too often, geophysical maps are interpreted without direct observation of the soil volume. This is particularly dangerous when EMI sensors are applied, because different objects at different depths can create similar anomalies (the "principle of equivalence," Lück, Ruhlmann, \& Spangenberg, 2005), making it difficult to invert the data to the real soil profile build-up. Therefore, there is a need for soil observations in depth. The proposed method to complement EMI prospection is to conduct soil auger observations along transects. According to Rapp and Hill (2006), soil augering is one of the most useful methods in geoarchaeology and can be combined with geophysics. Compared with other prospection methods such as field walking, shovel test pits, or excavation trenches (Roskams, 2001), soil augering combines direct observation of the subsoil with minimal soil disturbance and fast prospection of large areas.

The objective of this study was to investigate whether maps of ECa and MS allow the detection of complementary natural and archaeological anomalies and whether these maps could be interpreted in combination with soil auger observations. Therefore, a study area of 8 ha close to the Dutch coast of "Zeeland-Flanders" was surveyed. Historical records, archaeological relict mapping, and historical maps indicated the presence of a Medieval manor buried by flood sediments. The overlapping of natural soil variability due to recent geomorphological processes and anthropogenic soil changes required a geoarchaeological approach to interpret the site. In a first phase, the total field was prospected in a relatively low resolution; in a second phase, a small area of interest was investigated in more detail.

\section{SITE DESCRIPTION AND HISTORICAL BACKGROUND}

\section{Geographical Setting, Geomorphology, and Soil Characteristics}

The study area is situated in the polder area extending from the north of Belgium into the southeastern part of the Netherlands, with central coordinates $51^{\circ} 20^{\prime} 33.39^{\prime \prime}$ $\mathrm{N}$ and $3^{\circ} 33^{\prime} 4.18^{\prime \prime} \mathrm{E}$ (Figure 1). These polders represent a late Holocene landscape that consists mainly of alternations of marine and perimarine sediments (sand and silt) and peat beds (Vos \& van Heeringen, 1997; de Mulder et al., 2003).

Pleistocene loamy cover sands (Boxtel Formation) underlie the Holocene depositional sequence in most parts of the area. In the south of the coastal lowlands, cover sand ridges are present at the surface. The top of the Pleistocene substratum in general slants down to the north, toward the North Sea shore and the river Scheldt basin. The study site is situated in the central part of this area, where the top of the Pleistocene substratum is located at approximately 2.5-3 m below the surface. Soil maps on the 1:16,667 (Ovaa, 1957) and 1:50,000 scales (van der Sluys \& Ovaa, 1967) indicate a sandy clay soil at the study site. Closer inspection revealed that this is a 


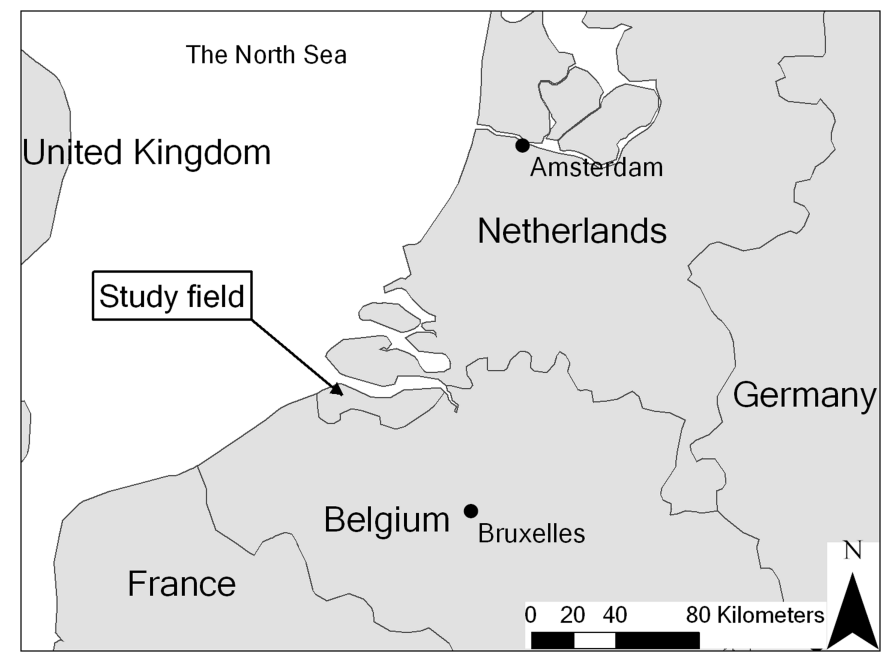

Figure 1. Location of the research site, in the border area of Belgium and the Netherlands.

young marine deposit from the end of the 16th to the middle of the 17th century. None of the maps indicated any anthropogenic disturbance of the natural sediments. The geomorphologic map on the 1:50,000 scale (Brus, 1987) was based on the soil and geological maps, which were of little use in understanding the geomorphologic processes in this submerged area.

\section{Historical and Archaeological Setting}

The Medieval site under study was a lost dependency of the Benedictine St. Peters Abbey of Gent (Belgium). The site, in Medieval texts called "Ruschevliet," has been an important center for agrarian exploitation and also functioned as storage for tithes. The complex was probably built in the 12 th century. The manor was temporarily an independent priory of the abbey, but from the second half of the 14th century on it was a farm that was leased out by the St. Peters Abbey (Vanslembrouck, Lehouck, \& Thoen, 2005). The Medieval site was lost during the Eighty Years War (1566-1648) between the Seventeen Provinces of the Netherlands and the Spanish authority. The area was inundated for military reasons, probably shortly after 1583. As a result, the old landscape was reshaped into a flooded environment for a period of 70 years. After the war, the Medieval landscape was completely reorganized; in the 17th century, a new landscape was established in a strict geometrical organization, which is still dominant today.

Historical geographical research during the 1950s could not identify the exact location of the Ruschevliet settlement (Gottschalk, 1955). Due to recent archaeological and historical research involving new methods, the center of the Medieval manor Ruschevliet was identified with high certainty somewhere within an agricultural 

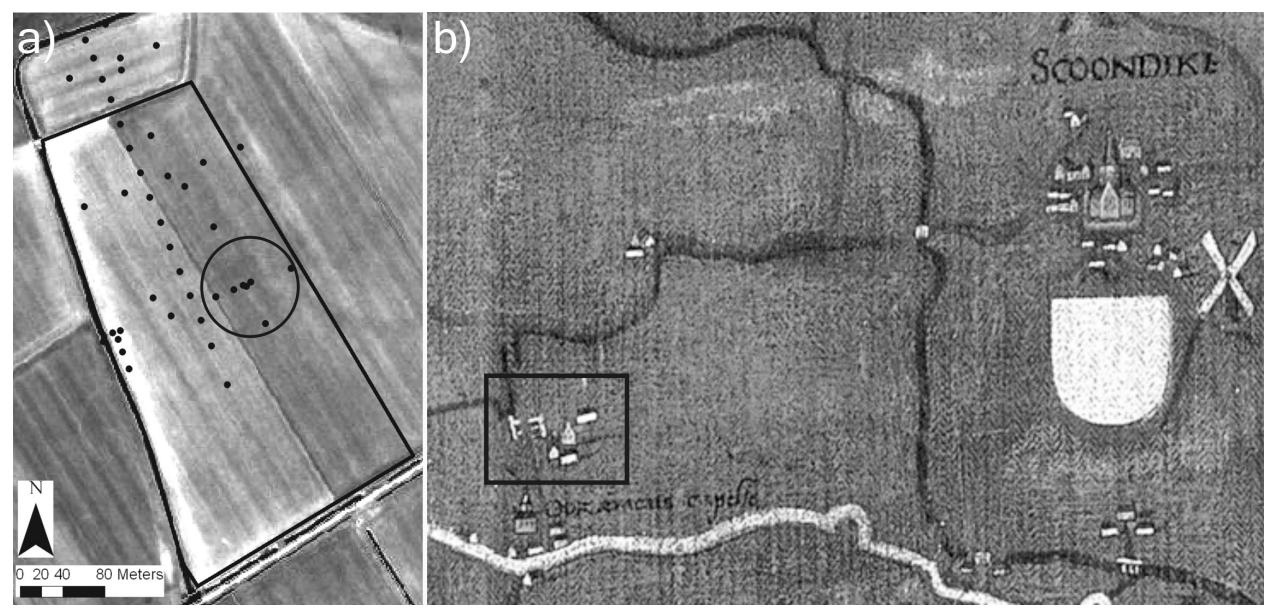

Figure 2. (a) The 8 ha study field delineated on an aerial photo, with the coarse auger locations depicted as black dots and the location of the moated site within the circle. (b) Part of the map of Pourbus (1571); the small rectangle indicates the possible location of the medieval manor "Ruschevliet," on the east side of the "Ruschevliet road."

field close to the village of Schoondijke in the autumn of 2004 (Vanslembrouck et al., 2005). Relict mapping, field walking, and a coarse auger campaign were then conducted on the field, resulting in the localization of a moated site (Figure 2a). Aerial photographs and a digital elevation model (DEM) were used as well. The DEM, the "Actual Height Model of the Netherlands (1996-2003)," was obtained from the Advisory Service Geo-Information and ICT Rijkswaterstaat. Height measurements with a minimum density of one point per $16 \mathrm{~m}^{2}$ were interpolated to a 5 by $5 \mathrm{~m}^{2}$ raster file with a maximum standard deviation of $16 \mathrm{~cm}$. The map of Pourbus (1571), shown in Figure 2b, revealed the presence of a large building, which could now almost certainly be identified as the demesne center Ruschevliet.

\section{SURVEY METHODOLOGY}

\section{EM38DD Sensor Configuration}

The EM38DD sensor (Figure 3a) is an electromagnetic induction (EMI) sensor, composed of a transmitter and receiver coil with an intercoil spacing of $1 \mathrm{~m}$. An alternating current is passed through the transmitter coil with a frequency of $14.6 \mathrm{~Hz}$, creating a primary magnetic field. The primary magnetic field induces eddy currents in the soil volume that in turn generate a secondary magnetic field, which is out of phase with the primary field. The primary magnetic field also interacts with the magnetic properties of the soil, which is measured as the in-phase response. The sensor consists of two units attached with perpendicular coil orientations that generate horizontal and vertical magnetic dipoles (DD = dual dipole), respectively. Each unit can be set to measure either the in-phase or out-of-phase (synonymous with 


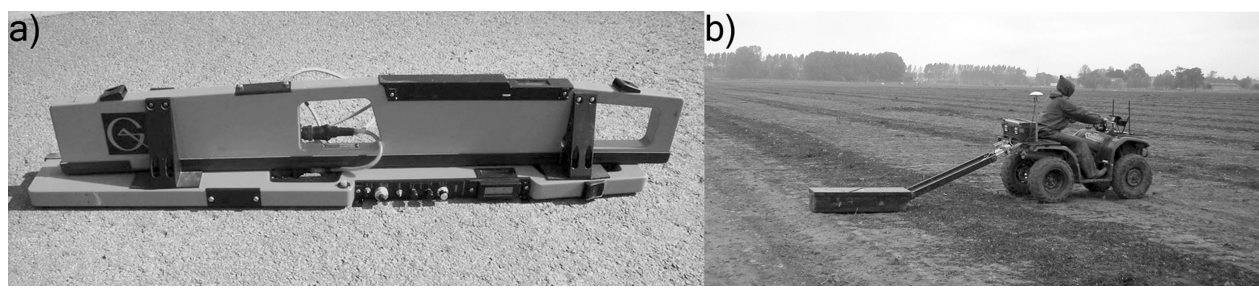

Figure 3. (a) EM38DD sensor; (b) mobile system operating on the 8 ha field.

quadrature-phase) component. The in-phase component is proportional to the magnetic susceptibility (MS) of the soil, whereas the out-of-phase component is proportional to the apparent electrical conductivity (ECa) of the soil.

Both properties have been used in geoarchaeological prospection and often yield complementary information. In general, the ECa in the soil is governed by electrolytic properties, which are influenced by soil constituents such as salts, clay, water, and organic matter (McNeill, 1980). Normally, the higher the content of one of these properties, the higher the electrical conductivity will be. Also, properties that affect the pore spacing of the soil volume (such as compaction) and the viscosity of the fluid (such as temperature) can influence the ECa reading. In the research area, saline soils were not encountered, so the influence of salinity was negligible. The MS is linked to Fe-oxides in the soil, such as magnetite and maghemite; pedogenic and anthropogenic processes result in creation and alteration of these minerals so that the MS is higher in the topsoil and in areas with heated or burned material, e.g., bricks or fireplaces (Clark, 1990). The ECa is expressed in $\mathrm{mS} \mathrm{m}^{-1}$, whereas the MS is dimensionless but is usually expressed in parts per thousand (ppt) of the EMI sensor in-phase response.

The mobile measurement platform (Figure $3 \mathrm{~b}$ ) consists of an all-terrain vehicle, pulling a polyethylene sled containing the EM38DD sensor and equipped with a differential corrected GPS (Trimble AgGPS332), with submeter accuracy. The data from the sensor were recorded at a maximum frequency of $10 \mathrm{~Hz}$ on a field computer, which simultaneously logs the GPS positions. Fields were measured in parallel driving lines, indicated by a light bar guidance system (Trimble AgGPS EZ-Guide Plus) controlled by the GPS. The light bar directed the driver to each line, with a line distance chosen at the start of the survey. Points within the line were spaced according to a chosen measurement frequency and driving speed. The distance offset between the GPS antenna and the sensor $(2.3 \mathrm{~m})$ was corrected in the data processing, using previous points in time as a direction reference.

The 8 ha field was measured in two days in a 2 by $2 \mathrm{~m}$ resolution, the first day with both coil orientations in ECa mode and the second day in MS mode (Survey 1, Figure 4a). The MS survey suffered from GPS satellite reception losses, so a number of lines had to be removed. Based on these first measurements, a smaller rectangular area of 120 by $230 \mathrm{~m}(2.76 \mathrm{ha})$ was measured at $10 \mathrm{~Hz}$, at a 1 by $1 \mathrm{~m}$ resolution, with both coils in ECa-mode (Survey 2, Figure 4a). Finally, a small area of interest was measured at 0.5 by $0.5 \mathrm{~m}$ resolution in MS mode (Survey 3, Figure $4 \mathrm{a}$ ). This resolution is adequate 
a)

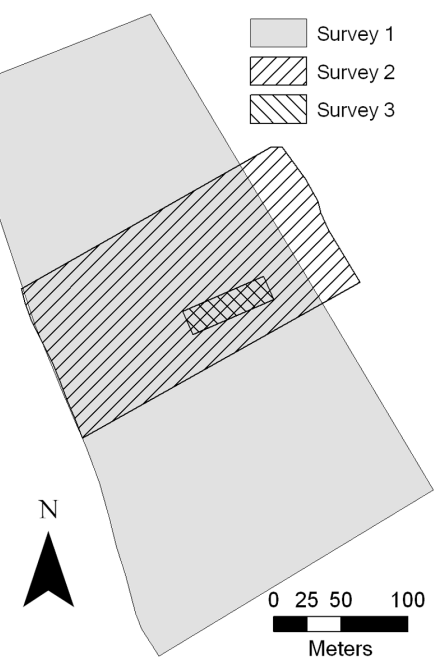

b)

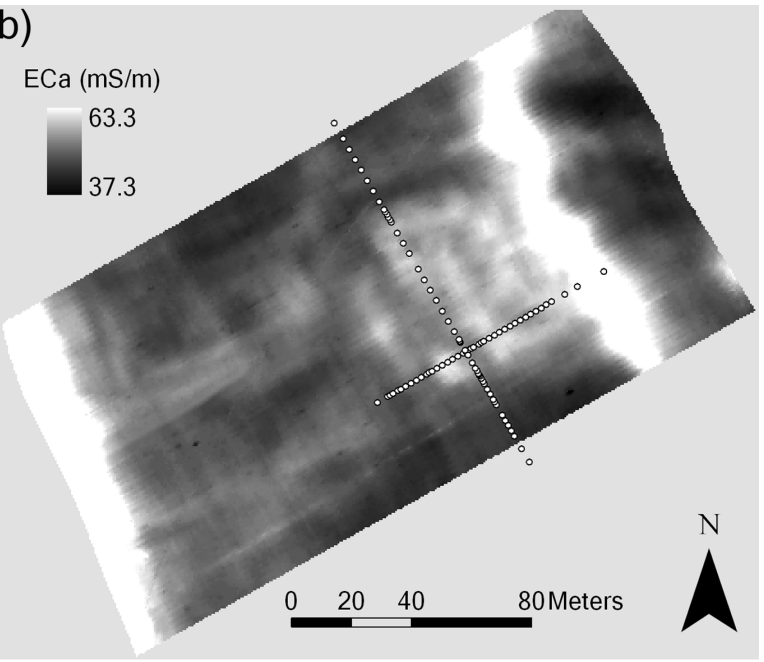

Figure 4. (a) Consecutive surveys in a 2 by $2 \mathrm{~m}$, a 1 by $1 \mathrm{~m}$, and a 0.5 by $0.5 \mathrm{~m}$ resolution. (b) Survey 2 : ECa map of the vertical dipole in a 1 by $1 \mathrm{~m}$ resolution.

to detect small archaeological features such as walls. All measurement points were interpolated to a grid with ordinary kriging, using the 10 closest measurement points.

\section{Soil Auger Survey}

The localization of the two auger transects was based on the results of the sensor maps (Figure 4b). The focus of this paper was on the occupation zone; cultural relicts in the vicinity of the site were not considered.

During the auger campaign, a Dutch hand auger (Edelman auger, $7 \mathrm{~cm}$ in diameter) was used for the first meter beneath the soil surface. For deeper horizons, a $1 \mathrm{~m}$ gouge auger ( $2 \mathrm{~cm}$ diameter) was used. Horizons and layers were described according to the classification system of the Dutch Soil Survey Institute (de Bakker \& Schelling, 1989), revised by ten Cate et al. (1995). During the soil survey, visible soil characteristics as well as the presence of archaeological artifacts (brick, pottery sherds, etc.) and ecofacts were observed. Soil texture and organic material were estimated according to reference soil sample analyses attached to the commentary of different soil maps available for the area. The presence of carbonates was tested with $\mathrm{HCl}$ (10\%), distinguishing among three classes: (1) without carbonates, (2) some carbonates, and (3) rich in carbonates. Marine sediments were originally rich in $\mathrm{CaCO}_{3}$, so this test is important to identify dissolution and/or precipitation processes.

Soil cores were taken at intervals of 2 to $4 \mathrm{~m}$ along a transect to enable the detection of cultural relicts such as building remains and large ditches. The sampling interval makes it hard to detect, for example, walls and small ditches or to have an understanding of formation processes, because soil observations between consecutive augers differed due to local natural and anthropogenic processes. Therefore, a more detailed sampling procedure (augering intervals of 0.5 to $2 \mathrm{~m}$ ) was applied at some locations. 

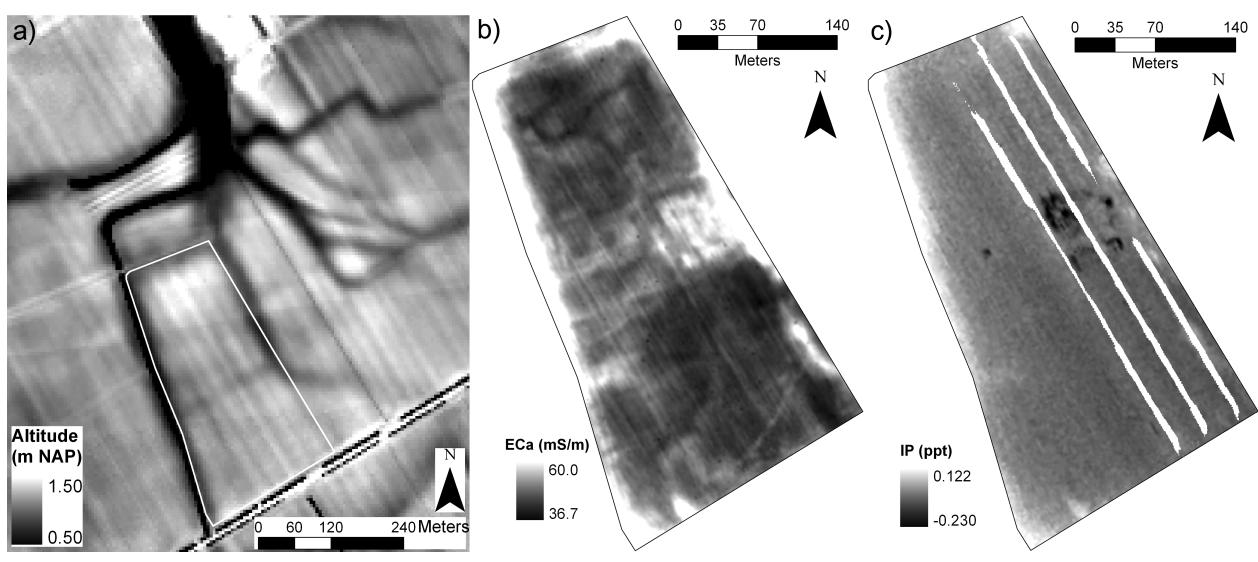

Figure 5. (a) DEM with the field delineation boundary. (b) Survey 1: ECa measured in the vertical dipole orientation. (c) In-phase (IP) measured in the horizontal dipole orientation.

Auger descriptions along the same transect were related to each other and graphically presented as a continuous vertical cross section. The altitude is expressed in m NAP ("Normaal Amsterdams Peil"), the reference level of the Dutch ordnance.

\section{RESULTS AND DISCUSSION}

\section{Prospection of Total Field}

The initial coarse auger observations campaign had indicated the presence of a moated site somewhere within the 8 ha field. A rough estimation of the ditch system surrounding the manor could be delineated, situated in the center-east of the field. However, the moated site was indistinguishable on the DEM (Figure 5a). A large marine channel running in the east of the field could be seen and was also encountered in the auger observations. The moated site was apparently located at the side of this channel, which probably developed into a waterway at the time of settlement. But the exact delineation of the site boundaries would require a very high number of auger observations. Because the coarse auger observations did not cover the whole field, there was a risk of missing important features present at the site.

The maps of the EM38DD Survey 1 provided answers to these research gaps (Figure 5b, c). The results show the ECa measured in vertical dipole orientation and the MS in horizontal dipole orientation. This configuration produced the best results and can be obtained in one run with the dual dipole configuration of the EM38DD. The ECa map was strongly related to both natural and artificial soil anomalies. The map shows the channel in the east as a high conductive zone, indicating finer sediments and/or higher wetness. Close to the field borders similar higher conductivities were found. The map also confirms the location of the moated site; moreover, it shows the sharp delineation of the ditch system surrounding the site, having a rectangular 
shape. In the southwest corner of the moated site, a smaller square delineation attracts more detailed attention. To the west of the rectangular moated site, the anomalies indicated the entrance way, probably connected to the Ruschevliet road. Parallel to the entrance way, the whole site was flanked by small ditches in the northern and southern parts that indicated the late-Medieval field system (Vanslembrouck et al., 2005). The ditch parcel in the southern part was transformed and reoriented, probably in the middle of the 17th century. This ditch system could be seen clearly on the DEM and on the ECa map. In the rest of the field, anthropogenic anomalies were also visible, but with no immediate interpretation.

The MS map is very homogeneous over most of the field, apart from the moated site itself, where archaeological traces were very clear. The two maps produced complementary anomalies, which together provide more information than just one map. Further research efforts were focused on the moated site, although the geophysical survey also revealed potentially interesting features in the rest of the field.

\section{Detailed Scale Prospection}

In the next stage, the moated site was investigated in detail with the high-resolution, mobile geophysical sensor at a 1 by $1 \mathrm{~m}$ resolution (Survey 2, Figure 4a). The resulting ECa map of the vertical dipole is shown in Figure 4b. The auger observations along the two transects are also shown, a first one oriented west-southwest to east-northeast (W-E) and a second one north-northwest to south-southeast (N-S).

Based on the auger observations, two vertical profiles along the transects were drawn, showing the subsoil heterogeneity down to a depth of $3.5 \mathrm{~m}$ (Figure 6). At the surface, the thickness of the actual plow layer varied between 15 and $45 \mathrm{~cm}$. Under the plow layer, marine sediments were found, originating from the inundation period of 1583-1651. These display a strongly varying thickness between 0 and $1.5 \mathrm{~m}$. This sediment has a sandy clay to clay texture, a light brown-gray color with iron oxide mottles and is rich in calcium carbonate. In these sediments, banks of shells of, for example, Mytilus sp. and Cerastoderma sp. were found as well. This inundation layer covers the late-Medieval cultural level, with several interesting structures such as ditches and walls. This cultural layer itself overlies another marine deposit, which developed during the Late Roman and Early Medieval period. The deposit originated from a channel system that eroded the underlying peat layer. This peat layer is (dark) brown, maximum $1 \mathrm{~m}$ thick, with fragments of reed and wood, and was deposited during the middle Holocene until the 3rd-4th century A.D. The deepest deposit found was Pleistocene sand at approximately $3 \mathrm{~m}$ depth.

The W-E transect locations are shown on the EM38DD maps in Figure 7. To compare the EM38DD maps with the W-E transect, the depth sensitivity of the sensor has to be taken into account, limiting the influence of features below $1.5 \mathrm{~m}$ under the soil surface.

The most striking features in the transect were a large ditch in the west and some areas with a lot of brick rubble. The ditch must have been approximately $10-14 \mathrm{~m}$ wide and 2.5-3 $\mathrm{m}$ deep. The dark gray layer at the west side of the ditch (profile numbers 662-666) was filled with rubble of brick and charcoal. This zone had a lower ECa than 

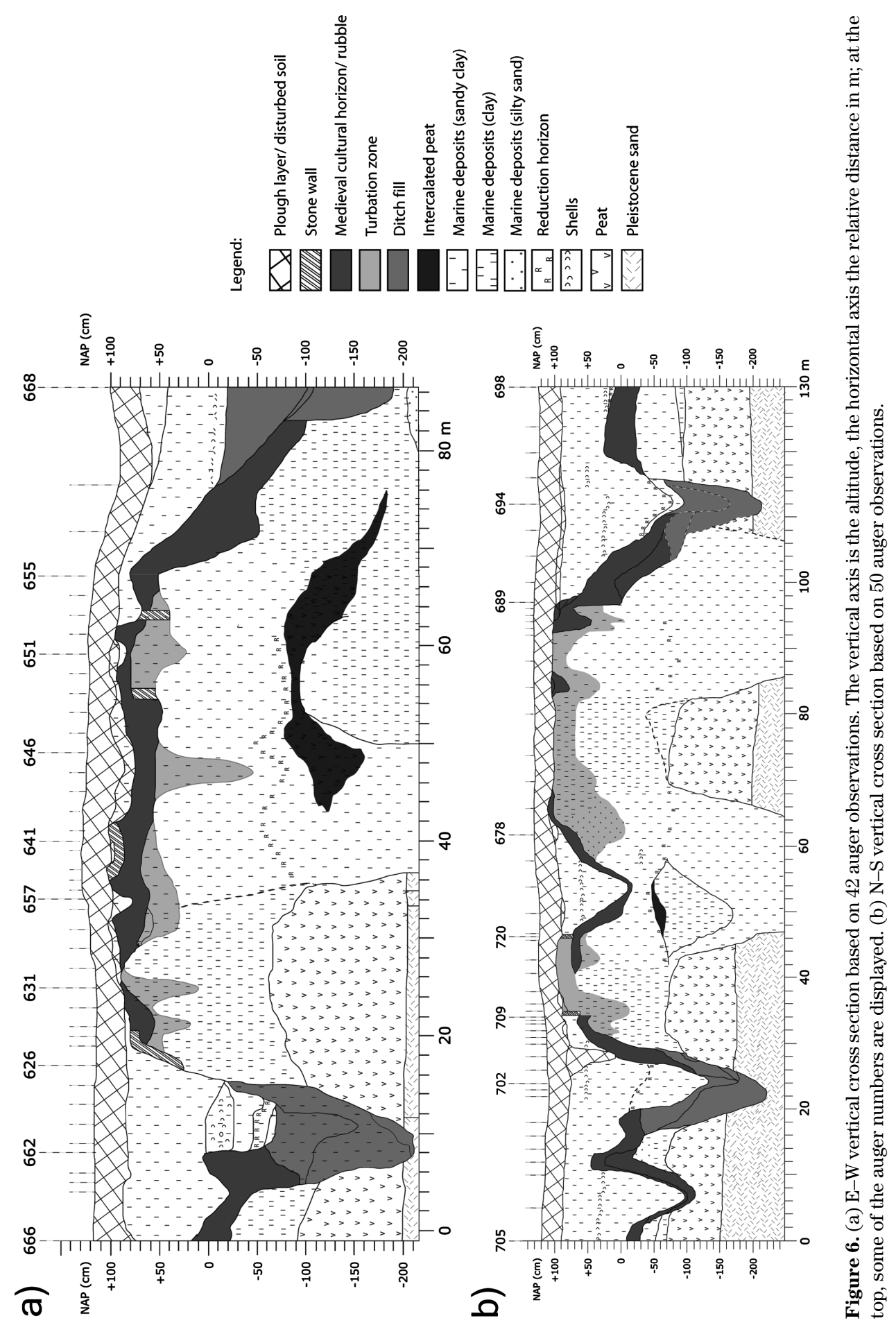


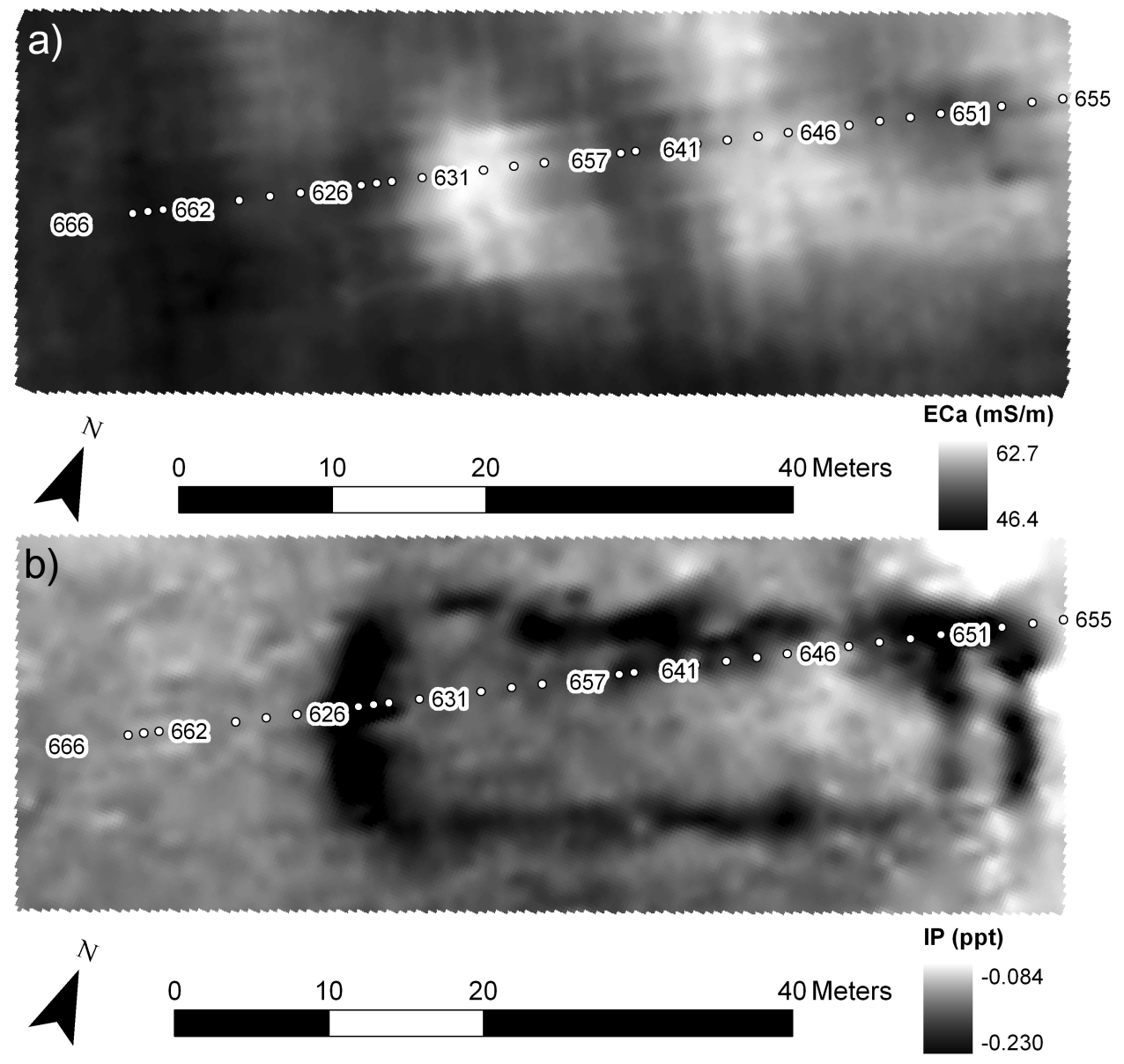

Figure 7. (a) Vertical dipole, ECa-map of Survey 2, cropped to the area of Survey 3; with the soil auger transect, some points were numbered to compare with Figure 6a. (b) Horizontal dipole, in-phase (IP) map interpolated from the 0.5 by $0.5 \mathrm{~m}$ measurements (Survey 3 ).

the ditch itself on the map (Figure 6a). The EM38DD measurements on the east flank of the ditch showed a clear anomaly in both maps: low ECa and high MS. On the MS map, a large rectangular structure of 42 by $13 \mathrm{~m}$ indicated the remains of a building. The transect at point 626 confirmed this with a high concentration of large brick fragments and mortar, which was difficult to penetrate with the auger. It is important to mention that these wall remains were found with the auger survey after the geophysical survey and that the horizontal spatial extent could be identified easily using the geophysical maps. Even the dimensions of the building were defined more accurately on the EM38DD maps. However, the auger observations gave valuable information on the nature of the sensor anomalies and their variation in depth. Just to the east of the ditch, the ECa rose from point 626 to a higher level of $10 \mathrm{~m} \mathrm{Sm}^{-1}$ 


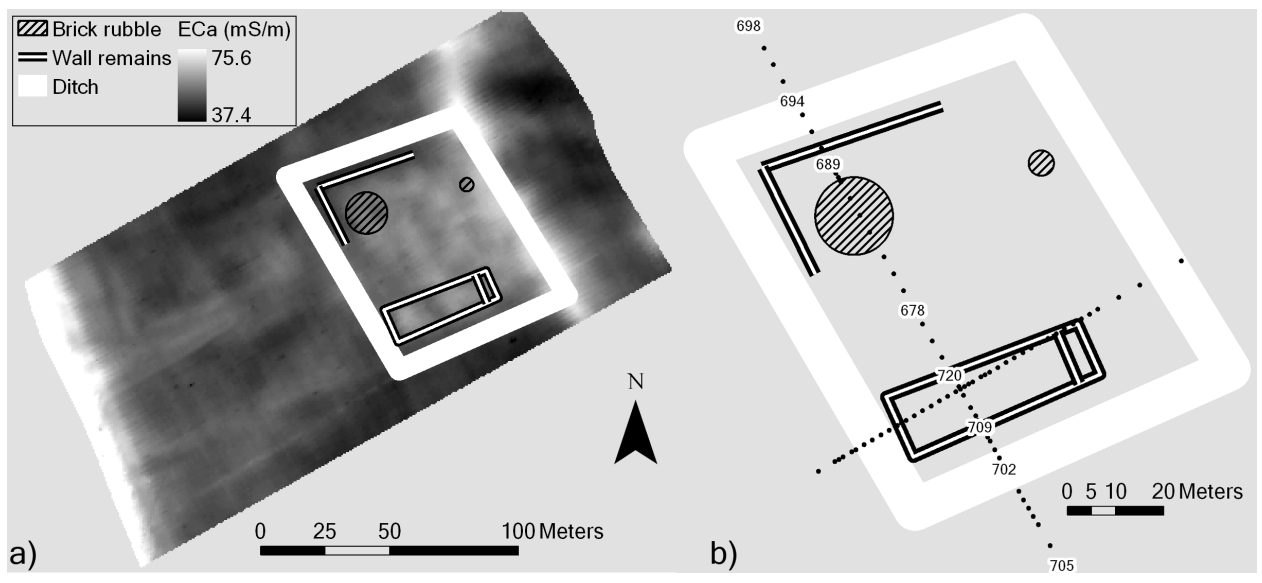

Figure 8. (a) Horizontal dipole, ECa-map of 1 by $1 \mathrm{~m}$ measurements, overlaid with the interpretation of the buried structures. (b) Buried structures overlaid with both transects. Relevant numbers of the N-S transect were labeled to use as a reference in the text.

difference at point 631 and decreased again at point 657 . Here the vertical profile showed a clay deposit occurring almost at the surface, the closest point being just under the plow layer at $25 \mathrm{~cm}$ depth. At approximately point 641 , the auger again collided with the remains of a brick wall. Here the transect crossed the north side of the building remains. A less clear structure was found at point 646 , with a relatively higher ECa. At around point 646, the marine deposits under the cultural level must have been mixed with sandy material up to $1.7 \mathrm{~m}$ depth, probably caused by deep digging. This feature could not be distinguished on the EM38DD maps because it did not contain enough magnetic or conductivity contrast with the surrounding soil. Furthermore, to the east of the profile, again two brick walls were found together with some brick rubble at the surface. The ECa displayed a relative low conductivity here and the MS showed remains of two parallel walls, $5 \mathrm{~m}$ apart. Farther east, there is a large channel that carved its way even in the Pleistocene sand, which corresponded with the channel on the DEM. The bedding of this channel developed into a waterway before late Medieval times and was also used as a ditch to border the east side of the moated site. This fill material could be distinguished by its slightly higher ECa values within the larger channel.

All information from the EM38DD maps and the soil auger transects was integrated in a simplified sketch of the ditch and the main rubble sites (Figure 8a). The locations of the two transects are shown in Figure 8b. Compared with Figure 6b of the N-S transect section, again the location of the ditch of the moated site corresponded well at both sides, as well as the building walls in the south of the site. The circled areas were places where the soil was highly disturbed with rubble. It is possible that another building or structure was located here, but this was probably leveled by the recent plowing of the field. The N-S transect showed that this zone is naturally elevated and the cultural layer is mixed with the current plow layer. In Figure 8a, other interesting 
features are visible, but because of the lack of auger observations it is dangerous to interpret those anomalies. The anomalies could be caused by several features, with different form and contrast at different depths. The transects also showed more small features, but these could not be extended horizontally because they were not distinguishable on the geophysical maps.

\section{CONCLUSIONS}

The mobile sensor configuration in combination with soil auger observations was able to detect and interpret interesting archaeological features. In the case study, the combined geoarchaeological approach was successful on two scale levels: (1) delineating the farm site within the total field and (2) mapping of the detailed features within a small area of interest. There was a large correspondence between the structures seen on the geophysical maps and the depth information of the soil observations. The ECa maps revealed the ditch of the moated site, the large channel part of a marine tidal system, large volumes of brick rubble, and other features dispersed over the 8 ha field that were not interpreted. The MS reacted strongly to the presence of brick wall remains and was more suitable to delineate these structures than the ECa. Other features were not visible in the MS map, even after contrast adjustment. But other magnetic features may be present, which could be detected with, for example, sensitive magnetometers. However, comparing different instruments was beyond the goal of this research.

Obviously, the limitations of the methodology have to be taken into account. First, the number of auger observations has to be sufficient to be able to connect individual transect points and interpret the soil profiles. Second, the geophysical survey with the EM38DD sensor is limited to a certain depth and horizontal resolution. Structures deeper than $1.5 \mathrm{~m}$ could not be detected. Moreover, the measured signal was an integration of the soil volume below the sensor; thus, it is difficult to know the depth of the measured anomalies. Third, not all anomalies found with the EM38DD could be explained by the auger transect; on the other hand, some features encountered with the auger did not have sufficient contrast to be distinguished by the EM38DD.

More aspects of the combined geophysical-soil auger approach remain to be investigated. There are a limited number of studies comparing EMI sensors with other types of sensors, combined with a thorough interpretation of the anomalies that were found with EMI and why others were not. Also, new EMI sensors are becoming available with varying coil spacing (e.g., Geonics Ltd., Dualem) or varying transmitter frequency (Geophex). These sensors could provide more information on structures at different depths. The auger point observations could be accompanied by sensor point measurements in a borehole (Dalan, 2006). But direct observation, including soil auger observations or test pits, will remain necessary for a good interpretation of any site. In the end, research has to show what is the most cost-effective combination of techniques for the maximum quality of geoarchaeological prospection. This study presented a relatively quick and low-cost methodology that could be useful for other prospections. 
This research is financially supported by the Fund for Scientific Research-Flanders (FWO Vlaanderen), the Netherlands Organization for Scientific Research (NWO), and the Flemish-Dutch Committee for Language and Culture (VNC). H. Vermeersch is thanked for support during the field work and for rearranging the figures. J.R. Mulder (Alterra, Wageningen) is thanked for his invaluable instructions on soil survey and comments on this paper.

\section{REFERENCES}

Benech, C., \& Marmet, E. (1999). Optimum depth of investigation and conductivity response rejection of the different electromagnetic devices measuring apparent magnetic susceptibility. Archaeological Prospection, 6, 31-45.

Brus, D.J. (1987). Geomorfologische kaart van Nederland 1:50 000. Toelichting op het kaartblad ZeeuwsVlaanderen. Haarlem, NL: University of Wageningen and Rijks Geologische Dienst.

Clark, A. (1990). Seeing beneath the soil. Prospecting methods in archaeology. Oxon, UK: Routledge.

Dalan, R.A. (2006). A geophysical approach to buried site detection using down-hole susceptibility and soil magnetic techniques. Archaeological Prospection, 13, 182-206.

de Bakker, H., \& Schelling, J. (1989). Systeem van bodemclassificatie voor Nederland. Wageningen: University of Wageningen.

De Mulder, E.J., Geluk, M.C., Ritsema, I., Westerhoff, W.E., \& Wong, T.E. (2003). De ondergrond van Nederland. Geologie van Nederland 7, Utrecht, NL: Nederlands Instituut voor Toegepaste Geowetenschappen TNO.

Desvignes, G., \& Tabbagh, A. (1995). Simultaneous interpretation of magnetic and electromagnetic prospecting for characterization of magnetic features. Archaeological Prospection, 2, 129-139.

Geonics (1998). Application of "dipole-dipole" electromagnetic systems for geological depth sounding. Technical Note TN-31. Ontario, Canada: Geonics Ltd.

Gottschalk, M.K.E. (1955). Historische geografie van Westelijk Zeeuws Vlaanderen. Deel I. Tot de St-Elisabethsvloed van 1404. Assen, NL: Van Gorcum.

Hill, I., Grossey, T., \& Leech, C. (2004). High resolution multisensor geophysical surveys for near-surface applications can be rapid and cost effective. The Leading Edge, 23, 684-688.

Kvamme, K.L. (2006). Integrating multidimensional geophysical data. Archaeological Prospection, 13, 57-72.

Linford, N. (1998). Geophysical survey at Boden Vean, Cornwall, including an assessment of the microgravity technique for the location of suspected archaeological void features. Archaeometry, 40, 187-216.

Lück, E., \& Eisenreich, M. (1999). Geophysical prospection of archaeological sites in Brandenburg, Germany. Archaeological Prospection, 6, 125-133.

Lück, E., Ruhlmann, J., \& Spangenberg, U. (2005). Physical background of soil EC mapping: Laboratory, theoretical and field studies. In J. Stafford (Ed.), Precision agriculture 2005 (pp. 417-424). Wageningen: Wageningen Academic Publishers.

Maillol, J.M., Ciobotaru, D.L., \& Moravetz, I. (2004). Electrical and magnetic response of archaeological features at the early Neolithic site of Movila lui Deciov, Western Romania. Archaeological Prospection, 11, 213-226.

McNeill, J.D. (1980). Electrical conductivity of soils and rocks. Technical Note TN-5. Ontario, Canada: Geonics Ltd.

Ovaa, I. (1957). De bodemgesteldheid van Westelijk Zeeuws-Vlaanderen. Stiboka Rapport 455. Wageningen, NL: University of Wageningen.

Rabbel, W., Stuempel, H., \& Woelz, S. (2004). Archaeological prospection with magnetic and shear-wave surveys at the ancient city of Miletos (western Turkey). The Leading Edge, 7, 690-693.

Rapp, G., \& Hill, L. (2006). Geoarchaeology. The earth science approach to archaeological interpretation (2nd ed.). New Haven, CT: Yale University Press.

Roskams, S. (2001). Excavation. Cambridge, UK: Cambridge University Press.

Tabbagh, A. (1984). On the comparison between magnetic and electromagnetic prospection methods for magnetic feature detection. Archaeometry, 20, 171-182.

Tabbagh, A. (1990). Electromagnetic prospecting. In I. Scollar, A. Tabbagh, A. Hesse, \& I. Herzog (Eds.), Archaeological prospection and remote sensing. Cambridge: Cambridge University Press. 
ten Cate, J.A.M., van Holst, A.F., Kleijer, H., \& Stolp, J. (1995). Handleiding bodemgeografisch onderzoek. Richtlijnen en voorschriften. Deel A: Bodem. Technisch Document 19A. Wageningen, NL: University of Wageningen.

Van der Sluys, P., \& Ovaa, I. (1967). Bodemkaart van Nederland, schaal 1:50 000. Toelichting bij de kaartbladen 53 Sluis en 54 West Terneuzen. Wageningen: University of Wageningen.

Vanslembrouck, N., Lehouck, A., \& Thoen, E. (2005). Past landscapes and present-day techniques: Reconstructing submerged medieval landscapes in the western part of Sealand Flanders. Landscape History, 27, 51-64.

Venter, M.L., Thompson, V.D., Reynolds, M.D., \& Waggoner, J.C. Jr. (2006). Integrating shallow geophysical survey: Archaeological investigations at Totógal in the Sierra de los Tuxtlas, Veracruz, México. Journal of Archaeological Science, 33, 767-777.

Vos, P.C., \& van Heeringen, R.M. (1997). Holocene geology and occupation history of the Province of Zeeland. In M.M. Fischer (Ed.), Holocene evolution of Zeeland (SW Netherlands) (pp. 5-110). Haarlem, NL: Mededelingen Nederlands Instituut voor Toegepaste Geowetenschappen TNO 59.

Received 1 August 2007

Accepted for publication 15 November 2007

Scientific editing by Armin Schmidt 